\title{
Statins Related Reduction In Major Ventricular Tachyarrhythmias (TV/FV) In Patients With Ischemic Cardiopathy Undergoing ICD Implantation For Primary Prevention
}

\author{
Massimiliano Manfrin*, Werner Rauhe and Roberto Cemin \\ Department of Cardiology, San Maurizio Regional Hospital, Italy
}

Received: March 15, 2018; Published: April 04, 2018

*Corresponding author: Massimiliano Manfrin, Department of Cardiology, San Maurizio Regional Hospital, Bolzano, Italy, Email: MASSIMILIANO.MANFRIN@sabes.it

\section{Abstract}

Purpose: to evaluate the anti-arrhythmic effect of statins in patients receiving an implantable cardioverter-defibrillator (ICD) for ventricular tachycardia/ventricular fibrillation (VT/VF).

Methods: 85 patients with ischemic dilated cardiomyopathy undergoing ICD implantation for sudden cardiac death (SCD) prevention (primary prevention) were enrolled in the study. 63 patients (72\%) were on treatment with statins (group 1), and 22 were not (group 2). The following end points were analyzed: recurrences of ventricular arrhythmias (VA) requiring ICD intervention and mortality.

Results: after a median follow up of 46.2 months (interquartile range 26.9 - 72.8 months) 28 patients (32.9\%) had at least one VA which required ICD intervention. Multivariate analysis showed that treatment with statins was the only independent predictor of arrhythmic events reduction (events requiring ICD intervention) ( $\mathrm{p}=0.042)$. Under the 63 patients of group $1,17(27 \%)$ had appropriate ICD intervention, while under the 22 patients of group 2, $11(50 \%)$ had appropriate ICD intervention ( $\mathrm{p}=0.0185)$. The mortality in group 1 was $28.6 \%$ (18 patients), while in group 2 was $50 \%$ (11 patients) ( $\mathrm{p}=0.0284)$.

Conclusion: the use of statins in patients with ischemic dilated cardiomyopathy undergoing ICD implantation was associated with a reduction in the risk of death and VT/VF episodes requiring ICD intervention. These findings suggest that statins may have anti-arrhythmic properties. These findings should be confirmed in a prospective, randomized clinical trial.

Abbreviations: ICD: Implantable Cardioverter-Defibrillator; SCD: Sudden Cardiac Death; CAD: Coronary Artery Disease; SCD: Sudden Cardiac Deaths; HR: Heart Rate; FVT: Fast Ventricular Tachycardia; VF: Ventricular Fibrillation

\section{Introduction}

Sudden cardiac death affects more than 250.000 patients yearly in the U.S. and, in patients with coronary artery disease (CAD), it is mainly determined by ventricular tachyarrhythmia [1]. Despite the evident public health relevance of fatal arrhythmic events, strategies for their prediction and prevention remain challenging [2]. Many trials have shown that the automatic implantable cardioverter-defibrillator (ICD) gave a survival benefit in primary prevention of sudden cardiac deaths (SCD) in patients with low ventricular ejection fraction due to a prior myocardial infarction $[3,4]$. Statins have been shown to reduce mortality and cardiac death in patients with CAD, but have also pleiotropic effects, independent of their cholesterol-lowering action [5,6]. In recent years, a number of observational studies have suggested that raised inflammatory markers are associated with a higher future risk of ventricular tachyarrhythmia and sudden cardiac death in a variety of clinical settings [7-10]. This, together with evidence indicating that statins reduce inflammation [11] as well as experimental findings on other biological effects of statins unrelated to their LDLcholesterol-lowering effects, has raised hope that such treatment may, in addition to its undisputed anti-atherosclerotic effects, have some anti-arrhythmic effects [12-14]. Recent data confirmed this hypothesis $[15,16]$. It is still unknown if statins have a direct effect in preventing life-threatening ventricular arrhythmias or if their effect is mainly mediated by an anti-ischemic action.

\section{Methods}

We analyzed the data of all consecutive patients with hypokinetic ischemic cardiopathy who underwent ICD implantation 
at the Regional Hospital of Bolzano in primary prevention for the SCD between 2006 and 2012. The indication of ICD-implantation followed the international guidelines for the prevention of SCD (patients with previous myocardial infarction, in optimal medical therapy, with a left ventricular ejection fraction $<35 \%$, elapsed at least 40 days after an acute ischemic event). We analyzed data of patients that at 31st December 2012 have at least 12 months of follow-up. The programming of the ICD was standard with two heart rate (HR) intervals of recognition: "fast ventricular tachycardia" ("FVT"), for ventricular arrhythmias with HR between 180 and 220 bpm, and "ventricular fibrillation" ("VF") for ventricular arrhythmias whose HR was over $220 \mathrm{bpm}$. Routine ambulatory ICD-control was performed every 6 months. After every visit all the data of the ICD were registered, in particular all the arrhythmias recorded and all ICD therapies. ICD therapies were classified as appropriate or not-appropriate. Particular attention was paid in recording type and dosage of statin`s therapy (Table 1).

\section{Table 1.}

\begin{tabular}{|c|c|c|c|}
\hline Type of Statin & Dosage (mg) & $\mathbf{N}^{\circ}$ of patients & Percentage \\
\hline \multirow{3}{*}{ Simvastatin } & 20 & 27 & $43 \%$ \\
\cline { 2 - 4 } & 40 & 10 & $16 \%$ \\
\hline \multirow{3}{*}{ Atorvastatin } & 10 & 5 & $8 \%$ \\
\cline { 2 - 4 } & 20 & 7 & $11 \%$ \\
\cline { 2 - 4 } & 40 & 5 & $8 \%$ \\
\hline \multirow{3}{*}{ Rosuvastatin } & 10 & 7 & $11 \%$ \\
\cline { 2 - 4 } & 20 & 2 & $3 \%$ \\
\hline
\end{tabular}

\section{Statistical Analysis}

All the data were analysed with Stata 12.0 (Texas U.S.A.) for Microsoft Windows. All the continuous variables are presented as median and 25th and 75th interquartile, while the categories variables are presented with percentage. Variables were tested for normal distribution with the Shapiro Wilk W test. Significance of differences and frequency distribution of values between the groups were assessed through the Mann-Whitney test for continuous variables and through the Chi-square test or the $\mathrm{F}$ test for categorical variables. $\mathrm{P}$ values of $<0.05$ were considered statistically significant.

\section{Results}

85 patients with ischemic cardiopathy undergoing ICD implantation for sudden cardiac death (SCD) prevention (primary prevention) were enrolled in the study. At the time of ICD implantation the average age was 66 years (median 68, interquartile range 62 - 72). 12 of them were in NYHA functional class I (14\%), 43 patients were classified as NYHA II (51\%), 25 as NYHA III (29\%) and 5 as NYHA IV (6\%). The median left ventricular ejection fraction was $27 \%$ (interquartile range $25 \%$ - 30\%). In most cases (61\%) a single chamber device (ICD-VVIr) was implanted, in 18 patients $(21 \%)$ a dual chamber device (ICD-DDDr), and in 15 patients (18\%) a biventricular device (ICD-CRT). The median follow-up was 46, 2 months (interquartile range 26,9 - 72,8). All clinical characteristics are summarized in Table 2.
Table 2.

\begin{tabular}{|c|c|}
\hline $\begin{array}{l}\text { Clinical Charcteristics } \\
\text { (85 patients) }\end{array}$ & $\begin{array}{l}\text { (interquartile range) } \\
\text { Percentage o median }\end{array}$ \\
\hline \multicolumn{2}{|l|}{ (interquartile range) } \\
\hline Age (years) & $68(62-72)$ \\
\hline Sex (men) & $76(89,4 \%)$ \\
\hline $\begin{array}{l}\text { Glomerular filtration rate } \\
\text { (MDRD) }\end{array}$ & $53,8(39,0-72,9)$ \\
\hline Diabetics & $30(35,3 \%)$ \\
\hline $\begin{array}{l}\text { Left ventricular ejection } \\
\text { fraction }\end{array}$ & $27 \%(25 \%-30 \%)$ \\
\hline Sinus Rhythm & $69(81,2 \%)$ \\
\hline Basal heart rate & $71(61-82)$ \\
\hline NYHA I & $12(14 \%)$ \\
\hline NYHA II & $43(51 \%)$ \\
\hline NYHA III & $25(29 \%)$ \\
\hline NYHA IV & $5(6 \%)$ \\
\hline ICD-VVIR & $52(61 \%)$ \\
\hline ICD-DDDR & $18(21 \%)$ \\
\hline ICD-CRT & $15(18 \%)$ \\
\hline
\end{tabular}

During the follow-up period 28 patients $(32,9 \%)$ experienced at least one ventricular arrhythmia treated by the ICD. In 13 cases the ventricular arrhythmia was in "FVT" range, and in 15 cases in the range of "VF. The 13 cases of "FVT" were treated first with Anti-tachicardial pacing (ATP), with $69 \%$ rate of success. When the ATP failed (4 patients) the patients were treated successfully with shock. All the shocks for "VF" were successful. The median timeinterval between ICD-implantation and first ICD-therapy has been 21,5 months (interquartile range 10,9 - 30,5). The 85 patients were divided into group A, patients on Statins (63 patients), and group B patients not receiving Statins (22 patients). There was no statistical difference of the medical therapy in the two groups, except for Amiodarone who was more used in the No-Satin Group (Table 3). Table 3.

\begin{tabular}{|c|c|c|c|}
\hline Therapy & $\begin{array}{c}\text { Statin Group } \\
\text { (n. 63) }\end{array}$ & $\begin{array}{c}\text { NO Stati Group } \\
\text { (n.22) }\end{array}$ & \\
\hline Beta-Blockers & 56 & 16 & $\mathrm{P}=0,1418$ \\
\hline Amiodarone & 9 & 10 & $\mathrm{P}=0,0065$ \\
\hline Ace-i & 63 & 22 & $\mathrm{P}=\mathrm{NS}$ \\
\hline
\end{tabular}

In group A 17 of 63 patients had a VA treated with ICDtherapy (27\%), whereas in group B 11 patients of 22 (50\%) had an appropriate ICD-intervention on VA $(p=0,0185)$.

The multivariate analysis showed that absence of statins was the only independent predictor of arrhythmic events $(p=0,042)$. Mortality in group A was 28,6\% (18 of 63), while in group B it was $50 \%$ (11 of 22) ( $\mathrm{p}=0,0284)$. The Hazard Ratio of appropriate ICDtherapy between the two groups was 0,47 (C.I. $0,22-1,00 ; p=0,05$ ): see Table 4 and Figure 1 shows the Kaplan-Meier curve time to first event in the two groups. Group a patients have a three years $25 \%$ lower probability to undergo an ICD therapy for VA. 


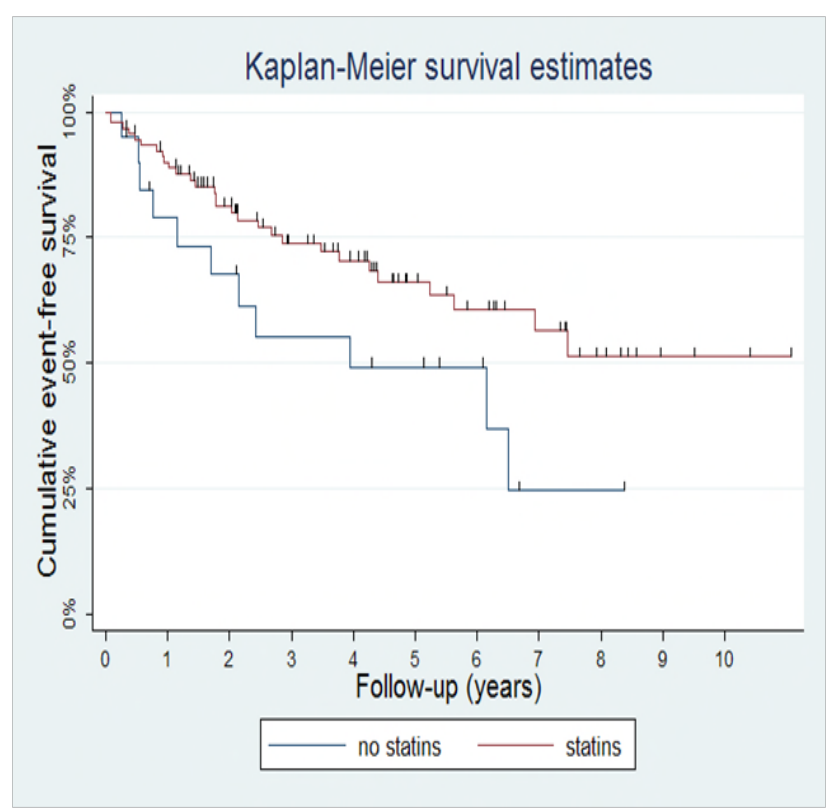

Figure 1: \% of patients free of 1.t. ventricular arrhythmias treated by ICD in the two groups $(\mathrm{p}=0.042)$.

Table 4: Hazard Ratio 0,47 (C.I. 0,22-1,00; $\mathrm{p}=0.05)$.

\begin{tabular}{|c|c|c|}
\hline & $\begin{array}{c}\text { Group A: patients on } \\
\text { Statins (63) }\end{array}$ & $\begin{array}{c}\text { Group B: patient } \\
\text { without Statin (22) }\end{array}$ \\
\hline $\begin{array}{c}\text { Appropriate ICD } \\
\text { intervention }\end{array}$ & 17 of $63(27 \%)$ & 11 of $22(50 \%)$ \\
\hline
\end{tabular}

\section{Discussion}

Main finding of this analysis was the fewer VT/VF episodes in statin user. 85 patients with ischemic cardiopathy who underwent ICD implantation for sudden cardiac death (SCD) prevention (primary prevention) were enrolled. After a median follow-up of 46.2 months (interquartile range 26.9 - 72.8 months) 32,9\% of the patients had at least one appropriate ICD-shock to interrupt a malignant ventricular arrhythmia. These data are similar to the data of MADIT II trial in which the estimate percentage at 3 years of appropriate shocks was 35\% [17]. In our opinion it is important to underline that not all appropriate shocks are equivalent to avoided SCD: some arrhythmias interrupted by the shock, could have resolved spontaneously after a few seconds, or, in particular for the "FVT", if hemodynamic tolerated, the patient could have reached the ER to resolve the arrhythmia before a fatal outcome.

The multivariate analysis of our group of patients showed absence of Statin therapy as the only independent predictor of arrhythmic events $(p=0,042)$. In group A (patients on Statins) 17 patients of 63 had a VA treated by ICD-therapy (27\%), while in group B (patients without Statins in therapy) 11 patients of 22 (50\%) had an appropriate ICD-intervention on VA ( $p=0,0185)$. The Hazard Ratio of appropriate ICD-therapy between the two groups was 0, 47 (C.I. 0, 22 - 1,00; p= 0,05). The Kaplan-Meier curve showed that patients on statins had a $25 \%$ lower probability of developing a VA treated by ICD-therapy at 3 years. Potential pathophysiological mechanisms for such a protective effect may include plaque stabilisation, changes to the transmembrane ion channel conduction, anti-oxidant and anti-proliferative effects, and decrease in the parasympathetic tone [15].

Supportive evidence for the anti-arrhythmic effect of statins derives from a number of non-randomized studies [18-20] and meta-analysis [21], showing a link between statin use and reduction of ventricular arrhythmic events. Statins have also been reported to improve regulation of coronary arterial tone and nitric oxidemediated endothelial function, inhibit cell proliferation, stabilize atherosclerotic plaques, have anti-inflammatory properties, and provide anti-oxidant effects. The mechanism by which statins reduce ventricular arrhythmias may relate indirectly to one or more of these effects. For example, the anti-oxidant and anti-cellproliferative effects of statins may play a role in plaque stabilization, thus contributing an anti-arrhythmic effect by reducing ischemiarelated ventricular Tachyarrhythmias.

Dietary polyunsaturated fatty acids have been reported to favorably alter the structure of the cardiac cell membrane and provide immediate anti-arrhythmic effects in lab experiments [2224]. Statins may similarly alter the lipid portions of the membrane through which the transmembrane segments of ion channels penetrate, thereby affecting ion-channel conductances. Statins may also have some membrane-stabilizing properties, but the exact mechanism by which statins may reduce arrhythmias is unknown. Convincing conclusions about the direct or indirect antiarrhythmic effect of statins could come from a similar study on non ischemic patients with hypokinetic cardiopathy.

\section{Study limitations}

This was a retrospective observational study and statin therapy was not randomized. The statin-user subjects may have been less sick than the no statin-user subjects, and there may have been incomplete statistical adjustment for observed imbalances. 


\section{References}

1. Mehta D, Curwin JA, Gomes A, Fuster V (1997) Sudden death in coronary artery disease. Acute ischemia versus myocardial substrate. Circulation 96(9): 3215-3223

2. Zipes DP, Camm AJ, Borggrefe M, Buxton AE, Chaitman B, et al. (2006) ACC/AHA/ESC 2006 guidelines for management of patient with ventricular arrhythmias and the prevention of sudden cardiac death. Eur Heart J 27: 2099-2140.

3. Moss AJ, Hall WJ, Cannom DS, James P Daubert, Steven L Higgins, et al. (1996) Improved survival with an implanted defibrillator in patient with coronary disease at high risk for ventricular arrhythmia. Multicenter Automatic Defibrillator Implantation Trial Investigator. N Eng J Med 335: 1933-1940.

4. Moss AJ, Zareba W, Hall WJ, et al. (2002) Prophylactic implantation of a defibrillator in patients with myocardial infarction and reduced ejection fraction. N Eng J Med 346: 877-883.

5. (1994) Scandinavian Simvastatin Survival Study Group. Randomised trial of cholesterol lowering in 4444 patients with coronary disease: the Scandinavian Simvastatin Survival Study (4S). Lancet 344: 1383-1389.

6. (1998) LIPID Study Group. Prevention of cardiovascolar events and death with pravastatin in patient with coronary heart disease and a broad range of initial cholesterol levels. N Engl J Med 339: 1349-1957.

7. Albert CM, Ma J, Rifai N, Stampfer MJ, Ridker PM (2002) Prospective study of c-reactive protein, homocysteine, and plasma lipid levels as predictors of sudden cardiac death. Circulation 105(22): 2595-2599.

8. Rahimi K, Watzlawek S, Thiene H, Secknus MA, Hayerizadeh BF, et al. (2006) Incidence, time course, and predictors of early malignant ventricular arrhythmias after non-ST-segment elevation myocardial infarction in patient with early invasive treatment. Eur Heart J 27(14): 1706-1711.

9. Blangy H, Sadoul N Dousset, Radauceanu A, Fray R, Aliot E, et al. (2007) Serum BPN, hs-C-reactive protein, procollagen to asses the risk of ventricular tachycardia in ICD recipients after myocardial infarction. Europace 9(9): 724-729.

10. Biasucci LM, Giubilato G, Biondi-Zoccai G, Sanna T, Liuzzo G, et al. (2006) $\mathrm{C}$ reactive protein is associated with malignant ventricular arrhythmias in patients with ischemia with implantable cardioverter-defibrillator. Hearth 92(8): 1147-1148.

11. Albert MA, Danielson E, Rifai N, Ridker PM (2001) Effects of statin therapy on C-reactive protein levels: the Pravastatin Inflammation/CRP Evaluation (PRINCE): a randomized trial and cohort study. J Am Med Assoc 286(1): 64-70.

12. Alberte C, Zipes DP (2003) Use of nonantiarrhythmic drugs for prevention of sudden cardiac death. J Cardiovasc Electrophysiol 14: S87-S95.
13. Kostapanos MS, Liberopoulos EN, Goudevenos JA, Mikhailidis DP, Elisaf MS (2007) Do statins have an antiarrhythmic activity? Cardiovasc Res 75: $10-20$.

14. Tamargo J, Caballero R, Gomez R, Nunez L, Vaquero M, et al. (2007) Lipid-lowering therapy with statins, a new approach to antiarrhythmic therapy. Pharmacol Ther 114: 107-126.

15. De Sutter J, Tavernier R, De Buyzere M, Jordaens L, De Backer G, et al. (2000) Lipid lowering drugs and recurrences of life-threatening ventricular arrhythmias in high risk patient. J Am Coll Cardiol 36: 766772 .

16. Mitchell LB, Powell JL, Gillis AM, Kehl V, Hallstrom AP, et al. (2003) Are lipid-lowering drugs also antiarrhythmic drugs? An analysis of the Antiarrhythmic Versus Implantable Defibrillators (AVID) trial. J Am Coll Cardiol 42: 81-87.

17. Moss AJ, Greenberg H, Case RB, Zareba W, Jackson Hall W, et al. (2004) For the Multicenter Automatic Defibrillator Implantation Trial II (MADIT II) research group: Long term clinical course of patients after termination of ventricular tachyarrhythmia by implanted defibrillator. Circulation 110: 3760-3765.

18. Fonarow GC, Wright RS, Spencer FA, Fredrick PD, Dong W, et al. (2005) Effect of statin use within the first 24 hours of admission for acute myocardial infarction on early morbidity and mortality. Am J Cardiol 96(5): 611-616.

19. Vyas AK, Guo H, Moss AJ, Olshansky B, McNitt SA, et al. (2006) Reduction in ventricular tachyarrhythmias with statins in the Multicentre Automatic Defibrillator Implantation Trial (MADIT-II). J Am Coll Cardiol 47(4): 769-773.

20. Goldberger JJ, Subacius H, Schaechter A, Howard A, Berger R, et al. (2006) Effects of statin therapy on arrhythmic events and survival in patients with nonischemic dilated cardiomyopathy. J Am Coll Cardiol 48(6): 1228-1233.

21. Wanahita N, Chen J, Bangalore S, Shah K, Rachko M, et al. (2010) The effect of statin therapy on ventricular tachyarrhythmias: a meta-analysis. Am J Ther.

22. Lamers J, Hartog J, Verdouw P, Hulsmann W (1987) Dietary fatty acids and myocardial infarction. Basic Res Cardiol 82(Suppl 1): 209-221.

23. Kang J, Leaf A (2001) Prevention of fatal cardiac arrhythmias by polyunsaturated fatty acids. Am J Clin Nutr 71(Suppl 1): 202S-207S.

24. Pound E, Kang J, Leaf A (2001) Partitioning of polyunsaturated fatty acids, which prevent cardiac arrhythmias, into phospholipids cell membranes. J Lipid Res 42(3): 346-351.
(C) This work is licensed under Creative

Submission Link: https://biomedres.us/submit-manuscript.php

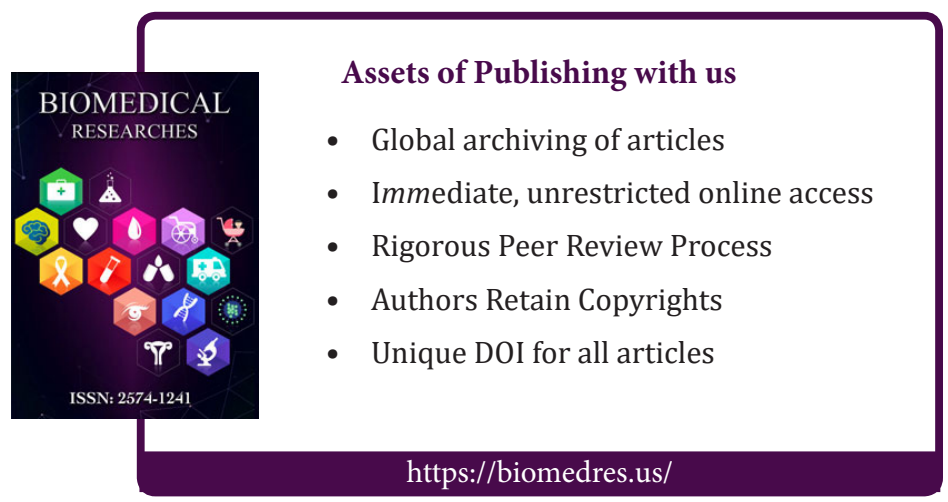

